\title{
SCN5A p.R965C in Brugada Syndrome: Effect of Nanomolecular Change
}

\author{
Sora Yasri ${ }^{1, *(D)}$, Viroj Wiwanitkit ${ }^{2}$ (D) \\ 1 Private Academic Consultant, Bangkok Thailand; sorayasri@outlook.co.th (S.Y.); \\ 2 Dr DY Patil University, Pune, India; wviroj@yahoo.com (V.W.); \\ * Correspondence: sorayasri@otlook.co.th (S.Y.);
}

Scopus Author ID 56022182600

Received: 26.06.2021; Revised: 30.07.2021; Accepted: 5.08.2021; Published: 5.09.2021

\begin{abstract}
Brugada syndrome is a syndrome causing abnormal electrolyte and electrocardophysiology. In an attack of Brugada syndrome, a patient might sleep and die without any other clear causes. Genetic underlying Brugada syndrome is widely studied. SCN5A p.R965C is a common genetic variant seen in an endemic area of Burgarda syndrome such as Southeast Asia. An assessment of the impact of SCN5A p.\$965C was performed using standard nanomolecular quantum calculation. According to the assessment, a decreased molecular weight due to mutation is observed, implying an increased SCN5A expression. The nanomolecular charge well explains the clinical problem of Brugada syndrome.
\end{abstract}

Keywords: SCN54; Brugada syndrome; nanomolecular.

(C) 2021 by the authors. This article is an open-access article distributed under the terms and conditions of the Creative Commons Attribution (CC BY) license (https://creativecommons.org/licenses/by/4.0/).

\section{Introduction}

Brugada syndrome is a syndrome that manifested with electrolyte imbalance and abnormal electrocardophysiology [1-6]. In an attack of Brugada syndrome, a patient might sleep and die without any other clear causes, known as sudden cardiac death [7-10]. It is recognized as an inherited disorder associated with the risk of cardiac dysrhythmia [1-10]. The atria and the ventricles have an abnormal electrophysiological function in Brugada syndrome; hence, a diagnosis of this syndrome is mainly based on characteristic electrocardiography (EK). The hallmark of the syndrome in EKG is coved type ST-segment elevation followed by a negative T-wave $\mathrm{f}$ the right precordial leads V1 to V2 [1-10]. A sodium-channel blocker test might stimulate the symptom. The prevalence varies among regions and ethnicities, affecting mostly males [1-10].

The etiology of Brugada syndrome is an interesting topic in clinical cardiology. It is believed that the genetic factor plays an important role in the pathogenesis of Brugada syndrome. It has a genetic disease pattern concordant with an autosomal dominant inheritance [1-10]. It is estimated that the prevalence of Brugada syndrome is about 50 in 100,000 people. The disease is endemic in East and Southeast Asia. The syndrome is a cause of sudden cardiac death in this area annually.

As an inherited disease, many new studies investigate the effect of genetic polymorphism. Genetic underlying Brugada syndrome is widely studied. SCN5A p.R965C is a common genetic variant seen in an endemic area of Burgarda syndrome such as Southeast Asia. An assessment of the impact of SCN5A p.R965C was performed using standard nanomolecular quantum calculation. 


\section{Materials and Methods}

The present study is a bioinformatics modeling analysis. The focused studied molecule is SCN5A p.\$965C. An assessment of the impact of SCN5A p.R965C was performed using standard nanomolecular quantum calculation based on standard technique according to the published technique described by the previous publication by Wiwanitkit [11, 12]. The standard quantum chemical calculation is for determining a change in molecular weight due to R965C polymorphism. The main aim of the calculation process is to trace the specific molecular weight alteration in variance and imply further impact on clinical phenotype.

Briefly, the first calculation of the molecular weight was done for the naïve polymorphism. Then a simulating change of genetic content according to $\mathrm{R} 965 \mathrm{C}$ was assigned, and the new molecular weight after simulating change was calculated in the same way of quantum chemical calculation. The derived final difference molecular weight between naïve and R965C mutation was finally assessed.

\section{Results and Discussion}

From analysis, the molecular weight change from the calculation is detected. A decreasing molecular weight change is observed. It can be seen that there is a change from 174 to $121 \mathrm{kDa}$ at the focused mutated site. The magnitude of change is equal to $53 \mathrm{kDa} / \mathrm{molecule}$. According to this molecular change, the final expression of SCN5A can be affected. A less number of the molecule will be required for the final expression of SCN5A, or it means there will be an increased expression.

The underlying genetic factor of Brugada syndrome is an interesting issue in clinical medicine. Due to the advanced clinical genetic laboratory, many genes are widely studied for their role in the pathogenesis of Brugada syndrome. Of several genes, SCN5A is an important gene that is mentioned for clinical association with Brugada syndrome. Basically, SCN5A plays a role relating to electrolyte physiology in human beings. Physiologically, the SCN5A gene plays a role in sodium channels, an important controller of the flow of positively charged sodium into the cell. The sodium channels consist of proteins produced from the SCN5A gene. Many sodium channels in cardiac muscle cells play important physiological roles in cardiac electrical signaling [13].

Since sodium is the main electrolyte requires for water and electrophysiology homeostasis, an aberration of SCN5A can result in many clinical problems. Since sodium channels mainly control and coordinate the myocontractions of the atria and ventricles, an abnormal heart rhythm might occur if sodium channels aberrate [13]. The mutation within SCN5A is reported, and it is believed to be an important factor for the pathogenesis of Brugada syndrome. In the present report, the nanomolecular quantum calculation can show a significant change of molecular weight due to SCN5A p.R965C, and it can explain the clinical problem of Brugada syndrome. This study's nanomolecular assessment technique is a standard technique and can clarify pathogenesis in many diseases [14-16].

In endemic areas of Brugada syndrome, hyponatremia is a common clinical characteristic of the patient. It is no doubt that overexpression of SCN5A is related to hyponatremia. Any pathologies that can result in hyponatremia can induced a clinical expression of Brugada like syndrome. Good examples are diabetic ketoacidosis, methanol intoxication $[16,17]$. 
The variation of Brugada syndrome manifestations is associated with genetic background and influenced by environmental factors [18 - 20]. Studies on pathogenesis relating to a genetic variant, as in this study, are recommended for clarifying the question of the presence of mixed clinical phenotypes of the syndrome.

\section{Conclusions}

Underlying genetic mutation plays an important role in the pathogenesis of Brugada syndrome. The present work assesses the effect of nanomolecular polymorphism and a significant change in mutated type compared to the naive type. The nanomolecular charge well explains the clinical problem of Brugada syndrome.

\section{Funding}

This research received no external funding.

\section{Acknowledgments}

This research has no acknowledgment.

\section{Conflicts of Interest}

The authors declare no conflict of interest.

\section{References}

1. Malik, B.R.; Ali Rudwan, A.M.; Abdelghani, M.S.; Mohsen, M.; Khan, S.H.A.; Aljefairi, N.; Mahmoud, E.; Asaad, N.; Hayat, S.A. Syndrome: Clinical Features, Risk Stratification, and Management. Heart Views 2020, $21,88-96$.

2. Campuzano, O.; Sarquella-Brugada, G.; Cesar, S.; Arbelo, E.; Brugada, J.; Brugada, R. Update on Genetic Basis of Brugada Syndrome: Monogenic, Polygenic or Oligogenic? Int J Mol Sci 2020, 21, https://doi.org/10.3390/ijms21197155.

3. Roomi, S.S.; Ullah, W.; Abbas, H.; Abdullah, H.; Talib, U.; Figueredo, V. Brugada syndrome unmasked by fever: a comprehensive review of literature. J Community Hosp Intern Med Perspect 2020, 10, 224-228, https://doi.org/10.1080/20009666.2020.1767278.

4. Sarcon, A.; Hsia, H.; Postema, P.G.; Wilde; A.A.M.; Patocskai, B.; Di Diego, J.M.; Antzelevitch, C.; Scheinman, M. Fractionated Epicardial Electrograms: Implication for Mechanism of the Brugada Pattern. JACC Clin Electrophysiol 2021, 7, 258-270, https://doi.org/10.1016/j.jacep.2020.12.009.

5. Behr, E.R.; Ben-Haim, Y.; Ackerman, M.J.; Krahn, A.D.; Wilde, A.A.M. Brugada syndrome and reduced right ventricular outflow tract conduction reserve: a final common pathway? Eur Heart J 2021, 42, 10731081, https://doi.org/10.1093/eurheartj/ehaa1051.

6. Pérez-Agustín, A.; Pinsach-Abuin, M.L.; Pagans, S. Role of Non-Coding Variants in Brugada Syndrome. Int J Mol Sci 2020, 21, https://doi.org/10.3390/ijms21228556.

7. Kim, Y.G.; Oh, S.K.; Choi, H.Y.; Choi, J.I. Inherited arrhythmia syndrome predisposing to sudden cardiac death. Korean J Intern Med 2021, 36, 527-538, https://doi.org/10.3904/kjim.2020.481.

8. Brugada-Terradellas, C.; Hellemans, A.; Brugada, P.; Smets, P. Sudden cardiac death: A comparative review of humans, dogs and cats. Vet J 2021, 274, https://doi.org/10.1016/j.tvjl.2021.105696.

9. Isbister, J.C.; Nowak, N.; Butters, A.; Yeates, L.; Gray, B.; Sy, R.W.; Ingles, J.; Bagnall, R.D.; Semsarian, C. "Concealed cardiomyopathy" as a cause of previously unexplained sudden cardiac arrest. Int J Cardiol 2021, 324, 96-101, https://doi.org/10.1016/j.ijcard.2020.09.031.

10. Rattanawong, P.; Kewcharoen, J.; Kanitsoraphan, C.; Barry, T.; Shanbhag, A.; Ko Ko, N.L.; Vutthikraivit, W.; Home, M.; Agasthi, P.; Ashraf, H.; Shimizu, W.; Shen, W.K. Does the Age of Sudden Cardiac Death in Family Members Matter in Brugada Syndrome? J Am Heart Assoc 2021, 10.

11. Wiwanitkit, V. Quantum chemical analysis of alternative pathways for iron activation step for artemisinin, a new antimalarial drug. J Infect 2006, 53, 148-151, https://doi.org/10.1016/j.jinf.2005.11.011.

12. Wiwanitkit, V. An explanation in nanostructure level based on the view of energy change for G333d mutation relating to drug resistance in HIV-1 reverse transcriptase. Indian J Med Microbiol 2008, 26, 202-203. 
13. Wilde, A.A.M.; Amin, A.S. Clinical Spectrum of SCN5A Mutations: Long QT Syndrome, Brugada Syndrome, and Cardiomyopathy. JACC Clin Electrophysiol 2018, 4, 569-579, https://doi.org/10.1016/j.jacep.2018.03.006.

14. Tamene, A.; Sattiraju, S.; Wang, K.; Benditt, D.G. Brugada-like electrocardiography pattern induced by severe hyponatraemia. Europace 2010, 12, 905-7, https://doi.org/10.1093/europace/euq034.

15. Yasri, S.; Wiwanitkit, V. FCGR polymorphisms and immune thrombocytopenia. Scand J Immunol 2020, 91, https://doi.org/10.1111/sji.12827.

16. Joob, B.; Wiwanitkit, V. Characteristics of BRAF V600K versus V600E: Effect of molecular weight change in melanoma. J Cancer Res Ther 2021, 17.

17. Yasri, S.; Wiwanitkit, V. Exons 1 and 10 Polymorphisms of LHCGR Gene and IVF Success. J Reprod Infertil 2020, 21.

18. Landa, E.; Sharifi, S.; Abraham, J.; Vigandt, E.; Munzinger, E. Brugada Pattern Phenocopy Induced by Diabetic Ketoacidosis. Cureus 2021, 13, https://dx.doi.org/10.7759\%2Fcureus.15066.

19. Monterrubio-Villar, J.1 Llinares-Moya, D. Brugada Phenocopy Induced by a Lethal Methanol Intoxication. Eur J Case Rep Intern Med 2020, 7, https://doi.org/10.12890/2020_001374.

20. Li, W.; Yin, L.; Shen, C.; Hu, K.; Ge, J.; Sun, A. SCN5A Variants: Association With Cardiac Disorders. Front Physiol 2018, 9, https://doi.org/10.3389/fphys.2018.01372. 